\title{
Presenting a Pattern for Increasing the Relative Efficiency of the Bank by Using Data Envelopment Analysis: (Case Study Agricultural Bank of Lorestan Province).
}

\author{
Hojjat Taheri Goodarzi ${ }^{1}$, Zahra Akbariani warmaziyar ${ }^{2}$ \\ ${ }^{I}$ Department Of Public Management, Borujerd Branch, Islamic Azad University, Borujerd, Iran \\ ${ }^{2}$ Master Of Public Management, Borujerd Branch, Islamic Azad University, Borujerd, Iran
}

\begin{abstract}
One of the factors in success of the developed countries is considering the efficiency of units. Efficient units not only do not waste the energy but also they obtain the resources properly. As, in every economy, bank are important institutions and essential posts and have a determinant role in developing the economy, their performance assessment has always been important. In today's world, considering the limitation of resources and excessive cost of providing them, proper decisions about the strategy of applying resources are significant. For the time being, domestic banks use transactional mass-based methods and methods based on performance operations, on the amount of equipment, and on obtaining resources in order to assess the performance \& ranking of branches. So efficiency index reflects the process of activity between inputs \& outputs of a branch which can be a more suitable criterion in assessing the branches performance. Data envelopment analysis is a theoretical framework in assessing, analyzing, \& measuring efficiency which do the function of evaluating Decision making units via solving its own models. In this study, for assessing relative efficiency of Agriculture Bank branches in Lorestan Province, two basic models in Data Envelopment Analysis have been used: input-oriented CCR, BCC. The results of this research show that, among 23 branches under evaluation in $C C R$ model, 6 branches are efficient and 17 are inefficient and among 23 branches in BCC model, 15 branches are efficient and 8 are inefficient. By applying AP model, branches have been ranked and a model has been presented for inefficient branches.
\end{abstract}

Keywords: Performance assessment, Data Envelopment Analysis, Input-oriented CCR, BCC models, Agriculture Bank.

\section{Introduction}

Market globalization in many countries \& the government's losing financial services, while competition is becoming more difficult, show new opportunities and in such dynamic environment you can hardly find a commercial unit that is not looking forward to grabbing these opportunities \& do not pay attention to constant improvement ways. In the developed technological world of computers \& electronic media where competition is growing so fast, performance assessment is one of the tools in constant improvement ways and it is of special importance in banking and different industries in recent years (Safari, 2011,2). As service and financial institutions, banks, which play an essential role in distribution of money \& wealth, have special place in the economy of each country. Positive \& effective activity of the banks can have influential effects on developing economic units and on increasing the products of each unit by flourishing in some economic fields.

In today's world, the main part of monetary exchanges is done by banks. Running the daily lives of people and also economic affairs of each country depends upon banks. Banks are representers of various services including the following which are among the most important ones: maintenance and transferring of money accumulation and distribution of governmental funds, changing different currencies into others,...( Khodaparasti, 2011). The lack of an integrated system of performance assessment, or in fact the lack of strategic methods of banking assessment leads to a kind of vagueness in their performance. As a specialized bank all over the country, Agriculture bank need designing an assessment and measuring system for assessing suitable efficiency in order to promote the level of performance and achieve the competitive advantage. Mathematical techniques reduce subjective effects and appeal to objective methods. These techniques, in measuring and evaluation, have the capability of accumulation of different theoretical trends. Data Envelopment Analysis is one of the mathematical and efficient tools in performance assessment.

In this research attempt has been made to answer the following questions:

1. Do the branches in large cities of province hare more efficiency?

2. Is there any direct relation between the score efficiency and the number of employees and fewer costs?

3. Can it be said that white developing inefficient branches, their efficiency increases? 


\subsection{The main methods of efficiency assessment}

\section{Research method}

Distinction should be made between two conceptions of efficiency: a) An efficiency which means obtaining the highest potential technical facilities, the ones which each agency can or cannot achieve. Such a definition may be possible theoretically, but its assessment is impossible in practice. b) an efficiency which is considered the best observed practical behavior of active agencies in industry. So agencies are compared to each other based on their performance (Jahanshahloo, 2008, 10-11). Data envelopment analysis is a Non-Parametric method in efficiency evaluation of Decision making units which have some inputs \& outputs as compared with the rhythmic amount of inputs.

\subsection{Return to scale}

The concept of Return to scale is proposed when we would lack to know what will happen to the outputs by changing the inputs in a specific ratio. In other words, return to scale is a long-term concept which reflects the ratio of increase in outputs to increasing in inputs. This ratio can be constant, ascending, or descending. With some assumptions, this discussion can be placed in data envelopment analysis based on which two important results are obtained. First, technical efficiency can be divided into managerial efficiency and scale efficiency. Second, small agencies are distinguished. The ratio of constant return to scale is true when the increase in inputs leads to the same in increase in outputs. The assumption of constant return to scale is applicable when agencies function in optimal scale. In deficient conditions \& environment, there are obstacles like investment limitations which make the agency not to function in optimal scale. In these cases variable return to scale is used.

\subsection{Review of Data Envelopment Analysis models}

\subsubsection{CCR, BCC models}

Assume that Decision making units of $\mathrm{j}=1,2, \ldots, \mathrm{n}$ by consumption if $x_{1}, x_{2}, \ldots, x_{n}$ respectively, produce the outputs $y_{1}, y_{2}, \ldots, y_{n}$. In addition, assume that DMU inputs $\&$ outputs are non-negative $\&$ each DMU has at least one positive input \& output. For assessment of DMU in which o $\varepsilon\{1,2, \ldots, \mathrm{n}\}$ the following models are used:

$$
\text { Miny }_{0}=\theta
$$

$$
\text { S.t } \cdot \sum_{j=1}^{n} \lambda_{j} y_{r j} \geq y_{r 0}
$$

$$
\sum_{j=1}^{n} \lambda_{j} x_{i j} \leq \theta x_{i 0}
$$

$\lambda_{j} \geq 0 \theta$

$$
\operatorname{Maxy}_{0}=\theta
$$

$$
\text { S.t: } \sum_{j=1}^{n} \lambda_{j} y_{r j} \geq \theta y_{r 0}
$$

$\sum_{j-1}^{n} \lambda_{j} x_{j} \leq x_{i 0}$

$\lambda_{j} \geq 0 \quad \theta$

The above models are known as CCR in which (1) is input-oriented \& (2) is output-oriented. If $\sum_{j=1}^{n} \lambda_{j}=1$ stipulation (1) is added to stipulations of models $1 \& 2, \mathrm{BCC}$ model is obtained in input-oriented \& output-oriented respectively.

\subsubsection{AP Model}

In 1993 Anderson \& Peterson proposed a method for ranking the efficient units in which appointing the most efficient unit was possible. With this technique, the score of efficient unit can be more than 1, so inefficient unit can be ranked like efficient units. The ranking of efficient units is as follow: 


$$
\begin{aligned}
& \text { Min } y_{\circ}=\theta-\varepsilon\left(\sum_{r=1}^{s} S_{i}^{+}+\sum_{i=1}^{m} S_{r}^{-}\right) \\
& S t: \sum_{j=1}^{n} \lambda_{j} x_{i g}+S^{-}{ }_{i}=\theta x_{i k} \quad\left(i=16 \ldots{ }^{6} m\right) \\
& \sum_{j=1}^{n} \lambda_{j} y_{r j}-S_{r}^{+}=y_{r k} \quad(r=16 \ldots 6 s) \\
& \lambda_{j} \geq \circ \cdot S_{r}^{-} \geq \circ \cdot S_{i}^{+} \geq \circ \quad \theta
\end{aligned}
$$

\subsubsection{Determining the type of return to scale}

One of the methods in setting the type of return to scale in units under assessment is Non-increasing returns to scale (NIRS).

$$
\begin{aligned}
& \mathrm{Min} \theta \\
& \text { s.t. } \mathrm{X} \lambda \leq \theta \mathrm{X}_{o} \\
& \mathrm{Y} \lambda \geq \mathrm{Y}_{o} \\
& N I \lambda \leq 1 \\
& \lambda \geq 0
\end{aligned}
$$

The nature orientation of type of return in inefficiency of scale for a specific agency is set as follow: Comparing the score of technical efficiency in Non-increasing return to scale in relation to scale, to technical efficiency of variable return to scale. If they both equal each other, the related agency encounter descending return to scale; otherwise, the condition of increasing return to scale is effective (Emami Meybodi, 2005, 14).

\subsection{Reference unit}

In DEA model, some measures should be regarded for improving inefficient unit performance in order to make these units reach the efficiency frontier. For inefficient DMU collection, reference unit is defined as follow: $\left\{\mathrm{j}: \lambda_{j}\right.$ in one of the optimal solution in evaluation, DMU is positive $\}$ (Jahanshahloo, Hosseinzadeh lotfi \& Nikoumaram, 2008, 58).

\subsection{Procedures}

In conducting this research four basic procedures have been considered:

1). Study, recognition \& exploitation of effective input indexes on assessment of relative efficiency of the bank: study and recognition of effective parameters in research domain is a prerequisite of every practical research. So in assessing the efficiency of Agriculture Bank, it was necessary to recognize the indexes of efficiency assessment with respect to data envelopment analysis. Given that, the previous studies \& research done in the banks were considered \& gathered. Then input \& output indexes were set based on Delphi techniques.

2). Setting inputs $\&$ outputs: This research has two inputs \& three outputs as follow: inputs: The number of employees \& the average of funds (administrative \& pertaining to employees). Outputs: The number of documents, the amount paid, \& people's deposits.

3). Gathering the required information for research: in this research 23 branches of Agriculture Bank in Lorestan Province were assessed.

4). Performing Data Envelopment Analysis: Mentioned before, for assessing the efficiency of Agriculture Bank input-oriented CCR , BCC model has been used in this study and for performing this model, maple software has been applied. After performing the model \& setting efficient \& inefficient branches, some strategies have been proposed to improve the efficiency of inefficient branches that are explained Lorestan Province.

\subsection{Applying Data Envelopment Analysis in Agriculture Bank}

By applying input-oriented envelopment CCR model and input-oriented envelopment BCC model in this research, assessing the relative efficiency of each branch of the bank has been attempted. Then in the next stage, scale efficiency in every branch has been calculated and with setting the type of Return to scale, Nonincreasing Return to Scale (NIRS) has been used that have been shown in chart1. 
Chart 1. The efficiency of branches, the type of efficiency and ranking (AP Model)

\begin{tabular}{|c|c|c|c|c|c|c|c|c|}
\hline \multirow[t]{2}{*}{$\begin{array}{c}\text { Ran } \\
\mathbf{k}\end{array}$} & \multirow[t]{2}{*}{$\mathbf{A P}$} & \multirow[t]{2}{*}{ Type } & \multirow[t]{2}{*}{ NIRS } & \multirow[t]{2}{*}{$\begin{array}{c}\text { Scale } \\
\text { efficiency }\end{array}$} & \multicolumn{2}{|c|}{$\begin{array}{l}\text { The amount of } \\
\text { Technical Efficiency in } \\
\text { the current state }\end{array}$} & \multirow{2}{*}{$\begin{array}{c}\text { Decision Making } \\
\text { Units } \\
\text { (Bank branches) }\end{array}$} & \multirow[t]{2}{*}{ Row } \\
\hline & & & & & BCC & CCR & & \\
\hline 19 & 0.58 & Decreasing & 1 & 0.58 & 1 & 0.58 & $\mathbf{A}$ & 1 \\
\hline 13 & 0.74 & Decreasing & 1 & 0.74 & 1 & 0.74 & B & 2 \\
\hline 4 & 1.24 & constant & 1 & 1 & 1 & 1 & $\mathbf{C}$ & 3 \\
\hline 5 & 1.05 & constant & 1 & 1 & 1 & 1 & D & 4 \\
\hline 15 & 0.71 & Increasing & 0.071 & $0 / 71$ & 1 & 0.71 & $\mathbf{E}$ & 5 \\
\hline 6 & 1.01 & constant & 1 & 1 & 1 & 1 & $\mathbf{F}$ & 6 \\
\hline 8 & 0.92 & Decreasing & 1 & 0.92 & 1 & 0.92 & $\mathbf{G}$ & 7 \\
\hline 12 & 0.75 & Increasing & 0.76 & 0.83 & 0.92 & 0.75 & $\mathbf{H}$ & 8 \\
\hline 11 & 0.76 & Increasing & 0.010 & 0.91 & 0.84 & 0.76 & I & 9 \\
\hline 18 & 0.67 & Increasing & 0.97 & 0.70 & 0.96 & 0.67 & $\mathbf{J}$ & 10 \\
\hline 17 & 0.69 & Increasing & 0.69 & 0.81 & 0.86 & 0.69 & $\mathbf{K}$ & 11 \\
\hline 7 & 0.97 & Decreasing & 1 & 0.97 & 1 & 0.97 & $\mathbf{L}$ & 12 \\
\hline 14 & 0.74 & Decreasing & 1 & 0.74 & 1 & 0.74 & $\mathbf{M}$ & 13 \\
\hline 16 & 0.71 & Increasing & 0.71 & 0.83 & 0.85 & 0.71 & $\mathbf{N}$ & 14 \\
\hline 10 & 0.78 & Increasing & 1 & 0.78 & 1 & 0.78 & $\mathbf{O}$ & 15 \\
\hline 2 & 1.53 & constant & 1 & 1 & 1 & 1 & $\mathbf{P}$ & 16 \\
\hline 22 & 0.45 & Increasing & 0.46 & 0.98 & 0.46 & 0.45 & $\mathbf{Q}$ & 17 \\
\hline 20 & 0.51 & Increasing & 0.51 & 0.87 & 0.59 & 0.51 & $\mathbf{R}$ & 18 \\
\hline 1 & 1.53 & constant & 1 & 1 & 1 & 1 & $\mathbf{S}$ & 19 \\
\hline 23 & 0.44 & Increasing & 1 & 0.44 & 1 & 0.44 & $\mathbf{T}$ & 20 \\
\hline 3 & 1.28 & constant & 1 & 1 & 1 & 1 & $\mathbf{U}$ & 21 \\
\hline 21 & 0.50 & Decreasing & 1 & 0.50 & 1 & 0.50 & $\mathbf{V}$ & 22 \\
\hline 9 & 0.81 & Increasing & 0.83 & 0.98 & 0.83 & 0.81 & $\mathbf{W}$ & 23 \\
\hline & & & & 0.8379 & 0.9266 & 0.7718 & Average & \\
\hline
\end{tabular}

Chart 2.The desirable state the current state and the percentage of required change for inefficient branches

\begin{tabular}{|c|c|c|c|}
\hline $\begin{array}{c}\text { The average of } \\
\text { costs }\end{array}$ & The number of employees & Inefficient br & \\
\hline 11924 & 33 & Current State & \multirow{3}{*}{$\mathbf{A}$} \\
\hline 19936.31 & 59 & Desirable State & \\
\hline 68 & 80 & The percentage of change & \\
\hline 3805 & 13 & Current State & \multirow{3}{*}{$\mathbf{B}$} \\
\hline 2797.08 & 19 & Desirable State & \\
\hline 27 & 50 & The percentage of change & \\
\hline 1038 & 2 & Current State & \multirow{3}{*}{$\mathbf{E}$} \\
\hline 439.245 & 1.436 & Desirable State & \\
\hline 58 & 29 & The percentage of change & \\
\hline 7430 & 14 & Current State & \multirow{3}{*}{$\mathbf{G}$} \\
\hline 6837.94 & 12.89 & Desirable State & \\
\hline 7.97 & 7.93 & The percentage of change & \\
\hline 735 & 3 & Current State & \multirow{3}{*}{$\mathbf{H}$} \\
\hline 576.12 & 2.332 & Desirable State & \\
\hline 22 & 23 & The percentage of change & \\
\hline 800 & 3 & Current State & \multirow{3}{*}{$\mathbf{I}$} \\
\hline 319.66 & 1.78 & Desirable State & \\
\hline 61 & 41 & The percentage of change & \\
\hline 5879 & 18 & Current State & \multirow{3}{*}{$\mathbf{J}$} \\
\hline 3948.76 & 12.09 & Desirable State & \\
\hline 32 & 33 & The percentage of change & \\
\hline 984 & 3 & Current State & \multirow{3}{*}{$\mathbf{K}$} \\
\hline 684.33 & 2.08 & Desirable State & \\
\hline 30 & 31 & The percentage of change & \\
\hline 798 & 5 & Current State & \multirow{3}{*}{$\mathbf{L}$} \\
\hline 773.87 & 4.84 & Desirable State & \\
\hline 3 & 4 & The percentage of change & \\
\hline 4350 & 12 & Current State & $\mathbf{M}$ \\
\hline
\end{tabular}




\begin{tabular}{|c|c|c|c|}
\hline 2286.2 & 8.85 & Desirable State & \\
\hline 48 & 27 & The percentage of change & \\
\hline 632 & 3 & Current State & \multirow{3}{*}{$\mathbf{N}$} \\
\hline 419.40 & 1.38 & Desirable State & \\
\hline 34 & 54 & The percentage of change & \\
\hline 6363 & 15 & Current State & \multirow{3}{*}{$\mathbf{O}$} \\
\hline 3751.92 & 11.58 & Desirable State & \\
\hline 42 & 23 & The percentage of change & \\
\hline 5496 & 14 & Current State & \multirow{3}{*}{$\mathbf{Q}$} \\
\hline 2478.88 & 6.32 & Desirable State & \\
\hline 54 & 55 & The percentage of change & \\
\hline 767 & 4 & Current State & \multirow{3}{*}{$\mathbf{R}$} \\
\hline 387.68 & 2.03 & Desirable State & \\
\hline 49 & 50 & The percentage of change & \\
\hline 2961 & 22 & Current State & \multirow{3}{*}{$\mathbf{T}$} \\
\hline 1303.56 & 9.68 & Desirable State & \\
\hline 55 & 56 & The percentage of change & \\
\hline 2404 & 21 & Current State & \multirow{3}{*}{$\mathbf{V}$} \\
\hline 1208.92 & 10.48 & Desirable State & \\
\hline 49 & 50 & The percentage of change & \\
\hline 626 & 4 & Current State & \multirow{3}{*}{$\mathbf{W}$} \\
\hline 505.61 & 3.6 & Desirable State & \\
\hline 20 & 10 & The percentage of change & \\
\hline
\end{tabular}

\subsection{The analysis of the results}

III. Findings

As seen in chart 1, in performing input-oriented CCR model, 6 branches out of 23 (about 27\% of branches) were recognized efficient. The calculated average efficiency of all centers equaled 0/7818. Inputoriented BCC model, 13 branches out of 23 (about $66 \%$ of branches) were recognized efficient. The average efficiency in this $0 / 9266$ which can be observed in chart 1 .

\subsection{Appointing model}

With solving the mentioned model for branches of Agriculture Bank, inefficient branches were recognized. Inefficient branches are those which have less than 1 efficiency. In order to make these branches efficient, some changes must be made to their inputs (because input-oriented was used). In chart 2, inefficient branches and their inputs, and also the desirable amount of these inputs for making these centers efficient have been shown. The current state row, in front of each inefficient branch, indicates the current amount of inputs related to the branch. Desirable state row indicates the amount of inputs by which inefficient branches reach the efficiency frontier. The third row shows the percentage of change in the current inputs of branches for making them efficient. For instance, inefficient branches of $\mathrm{J}$ should change the number of their current employees from 18 to the desirable level of 12 employees. In other words, they should decrease the number of employees up to $33 \%$, so in order to be efficient, inefficient units should reduce the amount of their inputs to the desirable level. In order to calculate the desirable amount of inputs in inefficient branches and turning them into efficient ones, forming inefficient unit method has been used: DMU model with combination of reference units

MODEL UNIT $=\left(\sum_{j \varepsilon \mathrm{E}_{o}} \lambda_{j}^{*} \mathrm{X}_{j}, \sum_{j \varepsilon \mathrm{E}_{o}} \lambda_{j}^{*} \mathrm{Y}_{j},\right)$

\subsection{Reference Branches}

Considering the following chart, it can be observed that, for every branch, among 17 inefficient branches, there are a combination of efficient branches with special coefficient and it show that if inefficient branches follow reference branches as a model, they can move toward efficiency. For example, when branch E follow branches U\& $\mathrm{P}$, which are located on the efficiency frontier, can move toward efficiency. In this chart, efficient branches C, D, F, P, S \& U have been used as reference units by inefficient branches 2, 6, 3, 16, 10, and 8 time respectively. 
Chart3. Reference branches, for inefficiency branches

\begin{tabular}{|c|c|c|c|c|c|c|c|c|}
\hline \multicolumn{8}{|c|}{ Reference Branches } & \multirow{2}{*}{$\begin{array}{r}\text { Inefficient } \\
\text { Branches }\end{array}$} \\
\hline $\begin{array}{l}\text { Unit } \\
\text { Coefficient } \\
4\end{array}$ & $\begin{array}{l}\text { Reference } \\
\text { Unit } 4\end{array}$ & $\begin{array}{l}\text { Unit } \\
\text { Coefficient } \\
\mathbf{3}\end{array}$ & $\begin{array}{l}\text { Reference } \\
\text { Unit3 }\end{array}$ & $\begin{array}{l}\text { Unit } \\
\text { Coefficient2 }\end{array}$ & $\begin{array}{l}\text { Reference } \\
\text { Unit2 }\end{array}$ & $\begin{array}{l}\text { Unit } \\
\text { Coefficient1 }\end{array}$ & $\begin{array}{l}\text { Reference } \\
\text { Unit1 }\end{array}$ & \\
\hline & & 1.57 & $\mathrm{U}$ & 7.49 & $\mathrm{P}$ & 0.43 & $\mathrm{D}$ & A \\
\hline & & & & 1.32 & $P$ & 0.55 & $\mathrm{C}$ & $\mathrm{B}$ \\
\hline & & & & 0.059 & $\mathrm{U}$ & 0.20 & $\mathrm{P}$ & $\mathrm{E}$ \\
\hline & & 0.055 & $\mathrm{P}$ & 2.67 & $\mathrm{~F}$ & 0.38 & $\mathrm{D}$ & $\mathrm{G}$ \\
\hline & & 0.29 & $\mathrm{~S}$ & 0.28 & $\mathrm{P}$ & 0.38 & $\mathrm{C}$ & $\mathrm{H}$ \\
\hline & & 0.016 & $\mathrm{U}$ & 0.11 & $\mathrm{~S}$ & 0.25 & $\mathrm{P}$ & I \\
\hline & & 0.56 & $\mathrm{U}$ & 1.37 & $\mathrm{P}$ & 0.086 & $\mathrm{D}$ & $\mathrm{J}$ \\
\hline & & 0.036 & $\mathrm{U}$ & 0.30 & $P$ & 0.007 & $\mathrm{D}$ & $\mathrm{K}$ \\
\hline & & 0.38 & $\mathrm{U}$ & 1.085 & $\mathrm{~S}$ & 0.193 & $\mathrm{P}$ & $\mathrm{L}$ \\
\hline & & 1.23 & $P$ & 0.46 & $\mathrm{~F}$ & 0.029 & $\mathrm{D}$ & M \\
\hline & & 0.0098 & $\mathrm{U}$ & 0.041 & $\mathrm{~S}$ & 0.21 & $\mathrm{P}$ & $\mathrm{N}$ \\
\hline & & & & & & 1.93 & $\mathrm{P}$ & $\mathrm{O}$ \\
\hline 0.50 & $\mathrm{U}$ & 0.28 & $P$ & 1.02 & $F$ & 0.0317 & $\mathrm{D}$ & $\mathrm{Q}$ \\
\hline & & 0.38 & $\mathrm{U}$ & 0.18 & $\mathrm{~S}$ & 0.026 & $\mathrm{P}$ & $\mathrm{R}$ \\
\hline & & & & 3.16 & $\mathrm{~S}$ & 0.56 & $P$ & $\mathrm{~T}$ \\
\hline & & & & 3.77 & $\mathrm{~S}$ & 0.49 & $\mathrm{P}$ & $\mathrm{V}$ \\
\hline & & & & 0.55 & $\mathrm{U}$ & 0.52 & $\mathrm{~S}$ & $\mathrm{~W}$ \\
\hline
\end{tabular}

\section{Conclusion \& Discussion}

4.1. Summary of the results: As it was proposed, the current methods of performance assessment of the banks are usually empirical. The most basic advantage of Data Envelopment Analysis creates an overview because it is the only methodology which relates all factors \& efficient agents to one another. In this research, considering input-oriented CCR,BCC model, the amount of efficiency in branches of Agriculture Bank has been calculated and efficient and inefficient centers have been recognized. The results have been presented in chart $1 \& 2$. Efficiency average in CCR, BCC models has been 0/7718 \& 0/9266 respectively. Regarding the results obtained form CCR model, it can be observed that out of six different centers only Borujerd county is one of the large cities in lorestan Province. Other efficient branches are in the small cities of the province and about 17 branches are inefficient. Ranking inefficient branches were done based on the amount of their inefficiency; for ranking efficient branches, Anderson-Peterson model was applied. For making these branches efficient, the degree of efficiency was calculated. Also the desirable amount of inputs for each branch and the amount of change in the current inputs of the branch were calculated in percent scale. The results have been presented in chart 2. In order to calculate the desirable amount of inputs in inefficient branches, the related model branches have been used which were a combination of reference branches (according to chart 3). In this chart, efficient branches C, D, F, $\mathrm{P}, \mathrm{S}$ and $\mathrm{U}$ have been used as reference for inefficient units $2,6,3,16,10$ and 8 times respectively and they can be regarded a successful branches. In order to answer the research question it can be said: The branches in small cities of the province have higher efficiency and with reducing the number of employees and costs, efficiency increases. In answering the third question it should be mentioned that in A, B, G, L, M, O \& V, with declining the development of the branch, the efficiency increases. In fact with development, efficiency decreases. In E, H, I, J, K, N, Q, R, T, W branches, with increasing development of the branch, the efficiency increases too.

\section{Suggestion based on research finding}

- It is suggested that the costs in inefficient branches be reduced and this can be done via controlling items of costs especially administrative costs.

- It is recommended that manager of branch affairs reduce the number of employees in the branch. Because many efficient branches do the operations which are similar to those of inefficient branches, or sometimes do the operations with greater volume compared to those of inefficient branches with fewer employs. It means that, in inefficient branches, some parts of manpower is not applied optimally and waste of human resources is observable.

- At the end, it is a good suggestion for the bank managers to recognize strong \& weak points in their system by using the scientific analysis of this research, and by controlling the inputs and also following efficient branches, especially reference branches; they can promote the efficiency frontier in Agriculture Bank branches. 


\section{References}

[1]. Emami Meibodi, Ali, (2005), the principle of measuring efficiency \& profiting. Tehran commercial studies end research institution publication.

[2]. Jahanshahloo, Gholamreza. Hosseinzade lotfi, Farhad. Nikoumaram, Hashem. (2008) Data Envelopment Analysis \& their application, science \& Research branch, Islamic Azad University publication.

[3]. Jahanshahloo, Gholamreza, (2008). Research in operation two in Mathematics. Tehran. PNU publication.

[4]. Hive Davoudi, Lida. Jahanshahloo, Hoda. Moazemi Goudarzi, Mohamad Reza. (2010) Correcting Saxetones Method for Ranking DMU in DEA. Applied mathematic magazine. Lahijan branch, No. 13.

[5]. Safaee Ghadiklaee, Rashid. (2011). Assessment of efficiency in Agriculture Bank branches in Mazandaran applying DEA.

[6]. Safaree. Ghazale (2011). Efficiency assessment in saderat bank branches applying two stage DEA.

[7]. Abiri, Gholam Hossein. (2002). Release: efficiency \& profiting in banking system: Bank \& Economy magazine, No . $24,30-34$.

[8]. Mehregan, Mohamad Reza (2004). Performance assessment of organizations: Quantitative approach using DEA. Tehran. Management College Publication, University of Tehran.

[9]. Al-Faraj,T.,Alidi,A. , and Bu-Bshait, K.(1993)." Evaluation of bank branches by means of data envelopment analysis"', International Journal of Operations and Production Management, 13,pp. 45-52

[10]. Berger, An. And Humphrey. D. B (1991). ," The domince of X-inefficiencies Over Scal and Product Mix Economies in Banking " . Journal of Monetary Economy in, No. 28, pp. 115-117

[11]. 11. Charnes, A.,Cooper, W.W., and Rhodes. E. (1978). "Measuring The Efficiency of Decision Making Units" . European Journal of operational ReSearch, Vol.2 No. 6pp. 429-444.

[12]. Charenes, A., Cooper, W. W. ,Lewin,A. Y.and Seiford, L.M. (1994). Data Envelopment Analysis: Theory, Methodolgy and Application, Klwer Academic Publishers, Boston, MA, pp. 5-33.

[13]. Chen, T., and Yeh,

[14]. Chen, T., and Yeh, T. (1998). Astudy of efficiency evaluation in Taiwanes banks. International Journal of Service Industry Management, 9,pp. 402-415.

[15]. Farrel,M.J.(1995). "The measurement of productive efficiency", Journal of the Royal Statistical Society, SeriesA, VOL. 120 NO . 3, pp. 258-281.

[16]. Golany, B., and Storbeck, J.(1999). A data envelopment analysis of the operational efficiency of bank branches. Interfaces, 29, pp. 14-26.

[17]. Ho. C., and Zhu, D. (2004). Performance measurement of Taiwanes commercial banks. International Journal of Productivity and Performance Management, 53,pp. 425-434.

[18]. Parkan, C. (1987). Measuring theefficiency of service operations: anapplication to bank branches. Engineering Costs and Production Economics, 12, pp.237-242.

[19]. Sherman, H., and Gold, F. (1985). Branch operting efficiency: Evaluation with Data Envelopment Analysis. Journal of Banking and Finance, 9, pp. 297-315.

[20]. Wu, D. Yang, Z., and Liang, L. (2006). Using DEA- neural network approach to evaluate branch efficiency of a large Canadian bank. Expert System with Applicatios, 31, pp. 108-115. 